\title{
O SIGNIFICADO DA CONDIÇÃO DE DESEMPREGADO: 0 CASO DOS EGRESSOS DA UNIVERSIDADE AGOSTINHO NETO, DE LUANDA, ANGOLA
}

THE MEANING OF BEING UNEMPLOYED: THE CASE OF THE EGRESSES FROM THE AGOSTINHO NETO UNIVERSITY, LUANDA, ANGOLA

\author{
EL SIGNIFICADO DE ESTAR DESEMPLEADO: EL CASO DE LOS EGRESADOS DE LA \\ UNIVERSIDAD AGOSTINHO NETO, LUANDA, ANGOLA
}

Marcos Júlio Dala Mandele*

\begin{abstract}
RESUMO
Este artigo apresenta a realidade psicossocial do desemprego e seus impactos na vida dos egressos da Universidade Agostinho Neto, na cidade de Luanda, Angola. Sintetiza as ideias construídas a partir da pesquisa realizada nessa cidade, no período de 2010 a 2012. Baseou-se em uma investigação de campo, de abordagem qualitativa, sobre os sentidos da condição de desempregado, tendo sido entrevistados 15 egressos dos cursos de Contabilidade e Auditoria, Direito, Economia, Filosofia, Física, Gestão e Administração Pública, Línguas e Literaturas, Matemática, Pedagogia e Sociologia. A amostra de participantes se deu pela estratégia da bola de neve. A discussão girou em torno dos conceitos de emprego e desemprego, tendo um marco teórico baseado em Araújo (2010), Beck (2010), Castel (2006), Gaulejac (2006), Jahoda (1987), Lhuilier (2011), Sanchis (1997) e Santos (2008). Recorreu-se também à pesquisa documental. A discussão dos dados das entrevistas foi realizada mediante a análise de conteúdo, de Bardin (2004). Os resultados da pesquisa demonstram que o desemprego acarreta dificuldades para os egressos se inserirem na sociedade e levar adiante seus projetos de vida. Verificou-se também que a formação universitária, em Angola, acaba formando estudantes para o desemprego e para uma série de incertezas profissionais.
\end{abstract}

Palavras-chave: Angola. Emprego. Desemprego. Desfiliação. Sofrimento.

\section{ABSTRACT}

This article presents the psychosocial reality of unemployment and its impacts on the lives of graduates of Agostinho Neto University, in the city of Luanda, Angola. It synthesizes the ideas built from the research carried out in that city, from 2010 to 2012. It was based on a field research, with

Texto recebido em 8 de setembro de 2019 e aprovado para publicação em 1º de março de 2020.

* Mestre em Psicologia no Programa de Pós-Graduação em Psicologia da Pontifícia Universidade Católica de Minas Gerais (PUC Minas); especialista em Gestão de Pessoas; graduado em Psicologia do Trabalho pela Universidade Agostinho Neto, Luanda,

Angola. E-mail: mjdmandele@gmail.com 
a qualitative approach, about the meanings of the unemployed condition, in which 15 graduates from the following courses have been interviewed: Accounting and Auditing, Law, Economy, Philosophy, Physics, Public Management and Administration, Languages and literature, Math, Pedagogy and Sociology. The sample of participants was given through the snowball strategy. The discussion revolved around the concepts of employment and unemployment, having a theoretical framework based on the following authors: Araújo (2010), Beck (2010), Castel (2006), Gaulejac (2006), Jahoda (1987), Lhuilier (2011), Sanchis (1997) and Santos (2008). Documentary research was also used. The discussion of the interview data was carried out through content analysis, by Bardin, (2004). The results of the research demonstrate that unemployment causes difficulties for graduates to enter society and carry out their life projects. It was also found that university education, in Angola, ends up training students for unemployment and a series of professional uncertainties.

Keywords: Angola. Employment. Unemployment. Disaffiliation. Suffering.

\section{RESUMEN}

Este artículo presenta la realidad psicosocial del desempleo y sus impactos en la vida de los egresados de Universidad Agostinho Neto, en la ciudad de Luanda, Angola. Sintetiza las ideas construidas a partir de la investigación realizada en esa ciudad, en el período de 2010 a 2012. Se basó en una investigación de campo, con un enfoque cualitativo, sobre los significados de la condición de desempleado, habiéndose entrevistado a 15 egresados de la Cursos de Contabilidad y Auditoría; Derecho; Economía; Filosofía; Física; Gestión y Administración Pública; Lenguas y Literaturas; Matemáticas; Pedagogía y Sociología. La muestra de participantes se formó a través de la estrategia de bola de nieve. La discusión giró en torno a los conceptos de empleo y desempleo, teniendo un marco teórico basado en los siguientes autores: Araújo (2010), Beck (2010), Castel (2006), Gaulejac (2006), Jahoda (1987), Lhuilier (2011), Sanchis (1997) y Santos (2008). También se utilizó la investigación documental. La discusión de los datos de la entrevista se realizó a través del análisis de contenido según propone Bardin (2004). Los resultados de la investigación demuestran que el desempleo genera dificultades para que los egresados ingresen a la sociedad y realicen sus proyectos de vida. También se constató que la educación universitaria en Angola acaba formando a los estudiantes para el desempleo y para una serie de incertidumbres profesionales.

Palabras-clave: Angola. Empleo. Desempleo. Desafiliación. Sufrimiento. 


\section{INTRODUÇÃO}

$\mathrm{N}$

este artigo, tomamos como elemento de discussão a condição de desemprego de egressos da Universidade Agostinho Neto, de Luanda, Angola. O desemprego, visto como invenção do mundo moderno, tem sua gênese nas transformações do mundo do trabalho. Castel (2005) escreve que ele é a manifestação visível de uma mudança profunda na conjuntura das sociedades salariais. A situação atual do mundo do trabalho afetou a condição salarial, provocando o desemprego em massa e a instabilidade nas situações de trabalho, além da inadequação ou da perda progressiva dos sistemas clássicos de proteção social. Daí a multiplicação de indivíduos que ocupam, na sociedade, uma posição supranumerária de “inempregáveis" ou empregados de modo precário. Essa questão, nos dias atuais, agrava-se fortemente com as mudanças bruscas dos vínculos e das relações de trabalho, com a institucionalização da terceirização e, mais ainda, com o fenômeno da "uberização", que vão desembocar nas degradantes formas de trabalho precarizado que, algumas vezes, está no limite entre o trabalho e o desemprego.

Essa condição de precariedade não se reduz, no entanto, apenas àqueles indivíduos com baixo nível de escolaridade. Ela abrange também pessoas com nível superior de escolarização, que disputam os escassos empregos disponíveis, como se vê na realidade angolana. $\mathrm{O}$ desemprego passa a refletir um problema social que causa instabilidade e insegurança entre os mais variados perfis de trabalhadores. Ele tem impactos significativos nos cursos de formação profissional de níveis superior e médio.

No caso de Angola, a problemática do desemprego tem a ver com a criação de monopólios e com a importação tanto de tecnologias dos países do Primeiro Mundo quanto da mão de obra de países aliados. O geógrafo brasileiro Santos (2008) foi um dos teóricos que analisou o desemprego, nos países do Terceiro Mundo, como consequência da importação de tecnologia e mão de obra dos países do Primeiro Mundo.

$\mathrm{O}$ interesse em estudarmos o desemprego se deveu ao fato de ele expressar a condição econômica, social e psicológica que mais atinge os recém-formados das faculdades em Angola, levando-os a um estado considerável de vulnerabilidade social. Castel (2005, p. 24) comenta que "a ausência da participação em qualquer atividade produtiva e o isolamento relacional conjugam seus efeitos negativos para produzir a desfiliação social". Em Angola, na cidade de Luanda, é comum ver pessoas com o diploma do ensino superior completo em situação de desemprego. Entre estes estão os egressos da Universidade Agostinho Neto 
(UAN), formados nas diversas áreas de conhecimento, como as Ciências Sociais, Humanas e Exatas. Tal fenômeno evidencia o crescente desencontro entre as expectativas de emprego desses sujeitos e as políticas públicas para o emprego no país.

Uma pesquisa em torno dessa temática tem importância, visto que contribui para a compreensão da condição do desemprego, vivido pelos egressos da UAN. Por extensão, ela reflete também a conjuntura do emprego e do desemprego, em Angola, onde as taxas de desemprego atingiram, no terceiro semestre de 2020, $34 \%$ da população ativa. Vale lembrar aqui que, como no resto do mundo, o mercado de trabalho foi também fortemente afetado pela emergência da covid-19 no país.

\section{REFERENCIAL HISTÓRICO E TEÓRICO}

\subsection{SITUAÇÃO SOCIOECONÔMICA DE ANGOLA}

O contexto sócio-histórico de Angola é demarcado por três períodos distintos: o Pré-Colonial, o Colonial e o da Pós-Independência. No que interessa especificamente à nossa investigação, daremos ênfases a este último.

No período de Independência, promulgada em 1975, estabeleceram-se, em Angola, duas situações distintas: a adoção de um regime político e econômico inspirado no modelo monopartidário, baseado em uma economia controlada pelo Estado, com planificação central, como nos países do bloco socialista. Esse regime foi adotado pelo partido no governo, o Movimento Popular de Libertação de Angola/Partido do Trabalho (MPLA/PT), em meio a uma guerra civil que se prolongou até fevereiro de 2002. Como toda economia era do domínio do Estado, os indivíduos ligados ao setor público tinham acesso a salário e ao fornecimento regular de bens de consumo, mediante distribuição de cartôes de abastecimento, como cartões da loja dos dirigentes, lojas francas e de minimercado do povo. Nessa época, várias empresas estatais prestavam desde serviços básicos aos mais complexos. Ao mesmo tempo, houve a ascensão da economia informal, que absorveu os indivíduos "excluídos" pelo sistema, por falta de certos requisitos, como o cumprimento do serviço militar obrigatório. Essa economia informal atingiu um nível ainda maior a partir de 1992, com a assinatura do cessar-fogo e os acordos de paz entre as forças militares do governo e a dos rebeldes. A informalidade tomou e ainda toma conta do mercado, sustentando grande parte das famílias angolanas. 
Desde o período da Independência de Angola até o fim do conflito armado, em 2002, as políticas para o fomento ao primeiro emprego não foram consideradas pelo Governo, pois todas as suas estratégias estavam voltadas para o setor militar, sustentando a guerra. E isso implica dizer que a questão do desemprego não era vista como um problema social que pudesse ter efeitos graves à saúde física, social e mental de quem o enfrentava. $\mathrm{O}$ desemprego não era considerado como um problema do Estado e da sociedade. O que prevalecia, para os que não tinham emprego na função pública, era o "salve-se quem puder".

Foi no ano de 2008 que as políticas públicas para o fomento ao emprego surgiram e ganharam importância por parte do governo angolano, com a criação da Lei $\mathrm{n}^{\circ} 1 / 06$, de 18 de janeiro de 2008, sobre o primeiro emprego, embora esta apresentasse falhas, tanto na aplicação como nos critérios de inclusão ou acesso ao emprego, como no caso das pessoas maiores de 35 anos. Com efeito, essa lei não corresponde à realidade do país, porque Angola vem de uma guerra civil que durou 27 anos. Muitos dos que hoje são excluídos, ontem, foram adolescentes e jovens que, à força, participaram diretamente da guerra, como soldados (militares). Essa dura realidade os impediu de terminarem o ensino fundamental e médio no período convencional da idade escolar.

Ao promulgar a Lei supracitada, os políticos não consideraram a expectativa de vida dos angolanos, que é de 46 anos de idade para homens e 50 para mulheres, o que ainda é reflexo da guerra civil e das condições sanitárias e de saúde. Além disso, eles não respeitaram os direitos da juventude, consagrados na Constituição angolana, de fevereiro de 2010, em seu artigo 81, sobre juventude e emprego, que diz:

Os jovens gozam de proteção especial para efetivação dos seus direitos econômicos, sociais e culturais, nomeadamente:

a) no ensino, na formação profissional e na cultura;

b) no acesso ao primeiro emprego, no trabalho e na segurança social (Constituição da República de Angola, 2010).

Essas políticas estão consagradas no Projeto Portal do Governo de Angola, Ministério da Administração Pública, Emprego e Segurança Social (MAPESS), aprovado pela Assembleia Nacional, que enfatiza a inserção na vida ativa da população desempregada, sobretudo os jovens à procura do primeiro emprego, desempregados de longa duração e cidadãos portadores de deficiência (Lei n. ${ }^{\circ}$ $1 / 06,2008)$. Essa lei tem como objetivo qualificar, valorizar e inserir o capital humano ativo nacional no mercado de trabalho. Nos seus artigos $1^{\circ}$ e $2^{\circ}$, capítulo 
I, a lei "Estabelece as bases gerais da política que proporciona a inserção no mercado de emprego de jovens à procura do primeiro emprego, prioritariamente com idade entre os 16 e 30 anos" (Lei n. ${ }^{\circ}$ 1/06, 2008).

\section{2.. ECONOMIA}

Quando começou a guerra civil, em 1975, logo após a Independência nacional, a economia angolana ficou devastada, e o país ficou dividido em zonas controladas pelos exércitos rivais. Assim, os rebeldes controlavam o setor diamantífero e o governo controlava o setor petrolífero. Isso impediu o desenvolvimento econômico do país como um todo. Cada um desses rivais canalizava para a guerra todos os recursos vindos tanto do petróleo como do diamante, deixando de fora o setor social e de serviços.

O fim do conflito armado possibilitou a diversificação da economia angolana, mas, apesar disso, o país se sustenta, prioritariamente, dos recursos vindo do petróleo. Como bem disse o ministro da economia da República de Angola, Abraão Gourgel, em entrevista dada ao Jornal de Angola: "O país se sustenta basicamente do petróleo", revelando também, que:

Durante o período de guerra, o Estado fez uso intensivo das empresas públicas para cobrir o mercado que apresentava ineficientes custos e receitas, impondo-se ao Ministério das Finanças, como entidade de tutela financeira, o dever de acudir sempre as empresas públicas, com transferência do orçamento geral do Estado para possibilitar a manutenção mínima dos serviços públicos e o auxílio de alimentação às populações (Gourgel, 2012).

Entende-se que essa atitude, de certa forma, contribuiu para o aumento do desemprego no país, pois o governo não tinha capacidade de criar mais postos de trabalho, uma vez que precisava acudir as empresas públicas.

É importante sublinhar que o modelo econômico angolano está baseado em atividades associadas de capital e de tecnologia, ligadas tanto ao setor petrolífero como diamantífero. As atividades petrolíferas e diamantíferas não conseguem garantir 1\% do emprego total aos trabalhadores angolanos, visto que as empresas exploradoras desses setores da economia nacional são estrangeiras e operam com tecnologia própria e capital humano expatriado e qualificado. As oportunidades de emprego nesses setores são, desse modo, limitadas para os angolanos, pois lhes falta qualificação ou know-how na área.

Atualmente, muitos empregos estão alocados na economia informal, sem qualquer regulamentação ou benefícios sociais para as pessoas que os ocupam. 


\subsection{EMPREGO E DESEMPREGO EM ANGOLA E NA ÁFRICA SUBSAARIANA}

O emprego é uma das mais importantes variáveis macroeconômicas e a alavanca do desenvolvimento social e econômico de qualquer país. Assim, quanto maior a proporção da população ativa desempregada, maiores são os índices de desperdício das possibilidades de desenvolvimento econômico e social do país. O emprego seria, pois, uma categoria econômica de grande importância para a estratégia de crescimento de Angola e peça fundamental nas políticas de promoção e participação dos cidadãos na composição do rendimento nacional. Rocha (2001, p. 152) afirma que, "em Angola, o emprego informal expressava-se em 74\% do total dos trabalhadores assalariados em Luanda".

Ainda em relação às causas do desemprego e à falta de empregabilidade em Angola, Rocha (2001) aponta outras origens, como o fato de a economia devastada e destruída pela guerra estar desarticulada pelo modelo centralista e administrativo da década de 1980, isto é, pelo controle total do Estado sobre a economia, enfraquecida, além disso, pela corrupção e pelas diversas disfuncionalidades institucionais. Esse autor também aponta, como uma das causas mais recentes do desemprego em Angola, a crescente inadequação das competências para ocupar o mercado de trabalho. Isso porque, como vimos, a maioria dos trabalhadores qualificados em Angola é importada de outros países. Essa constatação põe em questão, finalmente, no panorama das competências profissionais, a qualidade do ensino no país.

Angola é o país com a maior contingente de desempregados da África austral, tendo uma taxa total de desemprego que oscila entre $27 \%$ e $36 \%$, segundo as estatísticas de relatórios econômicos de instituiçóes como Centro de Estudo e Investigação Científica da Universidade Católica de Angola (CEIC) (Universidade Católica de Angola, 2010); Banco Mundial (2012); Universidade Católica de Angola (2011). Vale lembrar que os dados sobre o desemprego são imprecisos, tendo em conta, justamente, o peso da economia informal.

Esta pesquisa traz para o debate duas abordagens que refletem a realidade do emprego e do desemprego na África austral: a abordagem de Santos (2008) e a da Organização Internacional do Trabalho (OIT). A primeira explica, como já mostrado, que o desemprego nessa região resulta da importação de tecnologias dos países do Primeiro Mundo. Isso ocorre nos próprios governos africanos, principalmente quando abraçam e implantam as políticas de monopólios em seus países. Os monopólios de qualquer natureza repercutem negativamente na vida das populaçóes. Santos (2008) escreve também que o Estado participa do agravamento desse fenômeno, tanto pela política econômica quanto a fiscal. Isso 
se dá quando o próprio Estado adota modelos de crescimento importados, cria monopólios e concentra uma grande parte dos negócios em um pequeno grupo de alta renda (geralmente, políticos), reduzindo a capacidade de criar empregos em outras áreas do setor econômico. Ou seja, esse modelo de crescimento econômico é responsável por uma distribuição de renda cada vez mais injusta e impede a expansão do emprego. Tal prática cria um grande número de empregos para estrangeiros qualificados e um número reduzido de empregos para os nativos do país anfitrião.

Quanto às políticas fiscais, o país depende mais das linhas de crédito feitas entre Estados, sendo que a elas está atrelada, frequentemente, a corrupção, desvios de fundos e roubos. Isso desincentiva os investimentos de empresas privadas estrangeiras, impossibilitando a geração de mais empregos. Ao mesmo tempo, isso ocorre junto às constantes altas da inflação e desvalorização da moeda, como é no caso de Angola.

A segunda abordagem aponta, como possíveis causas do desemprego na África, a incapacidade dos estados africanos de investirem no desenvolvimento humano. O investimento do setor público é majoritariamente de capital intensivo (aquele que demanda grande quantidade de dinheiro para uma empresa operar em suas vendas ou serviços), frequentemente mal repartido, de modo a criar menos emprego do que o desejável. Além disso, o investimento é fortemente concentrado nas capitais dos países, o que cria desigualdades entre as regióes e entre os setores rural e urbano (Organização Internacional do Trabalho, 1997).

\subsection{ENSINO SUPERIOR EM ANGOLA}

No que toca ao ensino superior em Angola, ele tem crescido desde 2002. Essa evolução se deve ao aumento do número de cursos oferecidos por instituiçôes privadas. Segundo a Secretaria de Estado do Ensino Superior da República de Angola (Angola, 2008), de 1975 até 2005, o país registrou progressos notáveis no desenvolvimento do subsistema do ensino superior. Vemos, assim, que o ensino superior no país é relativamente recente. Foi fundado como estudos gerais universitários em 1962. A Universidade de Luanda foi criada em 1968 e, mais tarde, foi transformada em Universidade Agostinho Neto. ${ }^{1}$

\footnotetext{
${ }^{1}$ A Universidade Agostinho Neto localiza-se na Província de Luanda, fundada em 25 de janeiro de 1576 pelo explorador português Paulo Dias de Novais, sob o nome de São Paulo da Assunção de Loanda (Angola, 2012a). O ensino universitário em Angola foi institucionalizado, em 1962, pelo Decreto-Lei no 44.530, de 21 de agosto, que criou os Estudos Gerais Universitários de Angola, integrados à Universidade Portuguesa. Em 23 de dezembro de 1968, o Decreto-Lei no 48.790 transformou-os em Universidade de Luanda. Depois da Independência do país, a Universidade de Luanda foi transformada em Universidade de Angola - Portaria No 77-A/76. Todavia foi a partir do dia 24 de janeiro de 1985 que a Universidade de Angola passou a ser chamada de Universidade Agostinho Neto, em memória ao primeiro presidente de Angola e primeiro reitor da referida Universidade (Universidade Católica de Angola, 2011).
} 
Apesar desse crescimento exponencial das universidades, a qualidade do ensino, em muitas instituições, deixa a desejar. Elas estão mais preocupadas em cobrar "propinas"2 e obter lucros. Os cursos abertos nas faculdades não têm políticas de estágios obrigatórios para os alunos, e estes acabam saindo da formação sem qualquer prática. Muitos cursos são abertos, mas o país não oferece espaço político e social para se afirmarem, como é o caso do curso de Antropologia e Filosofia.

Hoje, na realidade angolana, as faculdades tornaram-se moda, objeto de prestígio e necessidade. Em outras palavras, se, para alguns, o curso superior tem um objetivo profissional, para outros, é apenas um luxo ou ainda um fator de promoção salarial. Nesse contexto, para muitos indivíduos, qualquer curso serve, desde que seus salários venham a ser aumentados.

O desemprego em egressos das universidades se tornou um problema grave. As questóes que envolvem o sistema educacional e o mercado de trabalho vêm ocupando um espaço crescente entre as preocupaçôes de muitos estudiosos. Sanchis (1997, p. 197) afirma:

É muito popular a crença de que existe uma falta de adequação entre egressos de vários níveis do sistema educativo e os recursos requeridos pelas diversas esferas do sistema produtivo. Este desajuste seria uma importante causa do desemprego e expressaria a necessidade de introduzir mecanismos corretores na evolução do sistema educativo para fazê-lo atender melhor às necessidades da economia.

Para o autor, o volume do desemprego em egressos revela que a trajetória da escola até o mercado de trabalho tem sido problemática, e o sistema educativo não está bem conectado com o mundo do trabalho. A posição dos egressos no mercado de trabalho continua se degradando. Sanchis (1997) escreve ainda que, no mundo, em geral, o desemprego decorre muito mais das configurações da economia do que da formação dos sujeitos. Mas, no caso angolano, é diferente, pois ele resulta tanto da configuração da economia como da formação deficiente e da corrupção instalada no país.

É importante dizer que a educação não pode resolver o problema do desemprego, mas cumpre, no caso, um importante papel complementar. Nesse sentido, ela deveria estar orientada tanto para a pesquisa como para o mercado de trabalho. Desse modo, contribuiria, ao mesmo tempo, para o enriquecimento científico do universitário e para a redução do desemprego.

${ }^{2}$ Termo usado em Angola para dizer pagamento das mensalidades escolares. 


\subsection{ASPETOS SOCIOECONÔMICOS DO EMPREGO E DO DESEMPREGO}

A discussão teórica sobre a temática aqui pesquisada transita entre o emprego e o desemprego, na vertente psicossocial. Para tal, apoiamo-nos nas teorias de Jahoda (1987), Castel (2010) e Demazière (2006). Para esses autores, o emprego tornou-se, sobretudo com o desenvolvimento do sistema capitalista, um dos elementos essenciais para se ganhar a vida em qualquer sociedade. $\mathrm{O}$ conceito de emprego está associado à institucionalização do trabalho, como trabalho assalariado e regular. Dessa forma, o emprego institucionalizado passou a ser uma categoria dominante para o reconhecimento e a valorização dos indivíduos, na ótica da sociedade de mercado, como indicador de sua segurança social e sucesso pessoal, bem como para a satisfação das necessidades de sobrevivência. A sociedade salarial deixaria a entender que cidadão é o sujeito que tem emprego ou, no mínimo, que está em busca do trabalho formal.

Assim, a importância do trabalho assalariado para a vida das pessoas na sociedade industrial não se fundamenta mais no trabalho em si, que independe do emprego. Seu valor remete não somente ao fato de que o emprego se torna a base da subsistência, ele também molda os comportamentos e condiciona a vida, a rotina e os hábitos de grande parte da população nas sociedades capitalistas. Desse modo, trabalho assalariado e formação ou profissão são tomados como fundamentos do modo de ser em sociedade. A vida gira em torno do trabalho assalariado, e a profissão se torna, nesse modelo, o elemento fundamental para se ganhar a vida (Beck, 2010). O autor comenta uma circunstância em que o valor adquirido pelo trabalho assalariado, na vida das pessoas, se mostra prevalente. Isso ocorre, por exemplo, quando dois amigos, separados pelo tempo, ou dois ex-colegas se encontram e se perguntam: "o que você é?" ou "o que você faz?". Diante dessas perguntas, as pessoas não respondem sobre o que fazem no tempo livre, mas sim com sua profissão. Portanto é a partir da profissão que se sabe quem ela é, o que também serve de paradigma de identificação e de avaliação de suas necessidades e capacidades pessoais, assim como da posição econômica e social que ela ocupa.

Nos primeiros estudos sociológicos sobre o desemprego, de 1939, realizados por Jahoda (1987), essa autora aponta as novas tecnologias e a nova divisão internacional do trabalho como a causa do desemprego nos países ricos, diferentemente do que ocorria em modelos históricos anteriores de trabalho. No entanto esse novo contexto não foi capaz de criar novos empregos para todos.

Hoje, a maioria das grandes empresas tende a não contratar mais a clássica "mão de obra", vigente no taylor-fordismo, pois seu discurso é de contratar o 
capital intelectual. No entanto, em Angola, ainda se vive uma situação contrária à dos países desenvolvidos, isto é, contrata-se a mão de obra análoga ao chamado "trabalho braçal". Por isso mesmo, não vamos abordar, para o caso de Angola, o atual panorama de desregulamentação e precarização do trabalho, ligado à terceirização e à "uberização", às quais nos referimos acima.

No estudo sobre o emprego e o desemprego, Jahoda (1987) também procurou estabelecer diferenças conceituais entre trabalho e emprego. A autora explica que, tanto na linguagem comum como na literatura das Ciências Sociais, os dois termos (trabalho e emprego) geralmente são utilizados como sinônimos, visto que ambos estão relacionados ao desempenho de um posto de trabalho para se ganhar a vida. No entanto ela esclarece a diferença entre os dois termos, de modo a facilitar sua compreensão. Assim, o emprego representa uma forma específica de trabalho que, no campo econômico e jurídico, é regulamentado por relações contratuais e supõe uma remuneração, ou seja, é o trabalho realizado em condições contratuais, em que se recebe uma remuneração material. Já o trabalho, em seu sentido trans-histórico, tomado como uma relação essencial entre o homem e a natureza, ou como a atividade que define o ser humano, distinguindo-o dos animais, envolve todas as outras formas de trabalho que não são economicamente relevantes e que diferem do conceito restrito de emprego, como o trabalho de um artesão, um escritor, os sociais, voluntários, entre outros. Portanto, o trabalho é um esforço da mente ou do corpo, realizado parcial ou totalmente com o propósito de obter algum benefício distinto da satisfação que deriva diretamente de uma ocupação remunerada. Nesse aspecto, em seu sentido antropológico, ele constitui a própria essência da vida.

De acordo com Jahoda (1987), estudar o mundo do trabalho a partir de uma perspectiva psicossocial implica marcar nitidamente as diferenças entre três formas de atividades: aquela que engloba a ampla definição dada por Marshall, em 1890, ou seja, o emprego regulado por um acordo contratual; em segundo lugar, certas atividades econômicas não reguladas por essa forma contratual (tal é o caso do trabalho exercido pelas empregadas domésticas, no contexto angolano); e finalmente, o trabalho por conta própria, seja ou não remunerado, como no caso do pequeno agricultor que trabalha para a própria subsistência. A partir dessa diferenciação, pode-se afirmar que a noção de desemprego deve ser contraposta à de emprego e não à de trabalho.

Em relação às definições sobre o desemprego, deve-se ainda observar que estas não são suficientemente claras nem uniformes. Segundo Jahoda (1987), a OIT tem tentado estabelecer uma definição que seja internacionalmente aceita, mas sem sucesso. Com efeito, as definiçốes legais variam de país para país. Em Angola, por exemplo, a definição do desemprego é dada pelo Instituto Nacional 
de Estatística (INE); no Brasil, pelo Instituto Brasileiro de Geografia e Estatística (IBGE); e na França, de acordo com Demazière (2006), pela ANPE (Agência Nacional de Emprego). Cada um desses órgãos é responsável por determinar quem deve ser considerado desempregado.

\subsection{IMPACTOS PSICOSSOCIAIS DO DESEMPREGO}

Do ponto de vista psicossocial, entende-se o desemprego como uma experiência que desestabiliza e traumatiza o sujeito, levando-o a estados de anomia e indiferença, o que pode significar uma existência esvaziada do sentido em si mesma. O desemprego representa uma privação que se torna ainda mais problemática quando se prolonga e se dilata seu espaço real (Jahoda, 1987; Demazière, 2006).

Como situação traumatizante, o desemprego desestrutura a solidez das relações com o outro, sendo seus efeitos, em geral, profundamente deletérios. Essas consequências variam de acordo com o sexo, a idade e o próprio tempo de desemprego. Apesar de o fenômeno ser estudado em países diferentes, ele tem efeitos relativamente idênticos para quem o vive. De acordo com Jahoda (1987), esses efeitos são tanto sociais quanto psicológicos. Uma das mais importantes consequências produzidas pelo desemprego é uma inevitável alteração da estrutura temporal. Esta se modifica e pode provocar transtornos psicológicos, pois os dias se alargam quando não há nada para se fazer (Jahoda, 1987). O desempregado se sente excluído e vive a experiência de isolamento social.

Em relação à exclusão, que Castel (2010) chama de desfiliação ${ }^{3}$,Lhuilier (2011) afirma que ser excluído do trabalho é não ter a possibilidade de demonstrar para si e para o outro sua eficácia ocupacional. O "sem trabalho" não pode colocar-se à prova do real, em termos do que lhe é possível. Ele vive uma experiência de "eu não valho nada", ele se vê degradado, em sua imagem, sente-se sem valor. Para a autora, a exclusão impossibilita o sujeito de se inscrever na relação com o outro. Nesse sentido, ser excluído pelo desemprego é viver a experiência de uma morte social, podendo também incluir as vivências de culpa e de vergonha social.

Diante dos efeitos provocados pelo desemprego, organizações internacionais, como a Organização Mundial da Saúde (OMS) e a Organização Internacional do Trabalho (OIT), passaram a tratá-lo como um problema mundial grave (Bernal, 2010). Com efeito, suas consequências são nefastas para quem o experimenta, e isso não deve ser subestimado. O desemprego, no caso de nosso estudo, torna-se

\footnotetext{
${ }^{3} \mathrm{O}$ termo desfiliação é usado para explicar a condição do homem na sociedade salarial. Ele é usado no sentido de não participação da dinâmica social, ficando privado do bem-estar e da proteção que a sociedade propicia a seus cidadãos. A exclusão está associada ao emprego e ao desemprego (Castel, 2010).
} 
mais grave ainda quando afeta os jovens egressos da Universidade de Luanda, em busca do primeiro emprego, porque eles estão numa fase decisiva da vida, na qual buscam construir sua identidade profissional e social.

\section{METODOLOGIA}

Para a concretização dos objetivos propostos neste estudo, foi realizada uma pesquisa qualitativa, operada em três fases, compreendendo as pesquisas teórica, documental e de campo. Optou-se pela abordagem qualitativa, pelo fato de esta procurar explorar e entender o significado que os indivíduos ou grupos atribuem a um problema social, possibilitando ao pesquisador levantar seus sentidos e as formas como os participantes os vivenciam (Creswell, 2010).

A pesquisa teórica buscou compreender as principais contribuições relativas ao tema de estudo, considerando-se a produção já existente (Diez, \& Horn, 2005). Nessa fase, foram consultados livros, artigos de periódicos, teses e dissertações que continham informações relativas ao assunto estudado. A pesquisa documental trouxe dados consultados em documentos oficiais e não oficiais, relativos ao tema e disponíveis ao público em geral, como leis, relatórios e inquéritos. Documentos como o Projeto Portal do Governo de Angola e o Jornal de Angola retratam a situação do desemprego, assim como as políticas de fomento ao emprego.

$\mathrm{Na}$ fase da pesquisa de campo, os dados foram produzidos por meio de entrevistas semiestruturada realizadas com 15 participantes egressos de diversos cursos da Universidade Agostinho Neto, na Província de Luanda, Angola, com idades compreendidas entre 25 e 35 anos. Alguns dos participantes são naturais desta cidade e outros apenas residentes, em busca de ensino superior, inexistentes em suas províncias de origem.

Os dados coletados foram tratados com procedimentos próprios da pesquisa qualitativa, especialmente pela análise de conteúdo de Bardin (2004).

\section{PESQUISA DE CAMPO}

\subsection{ANÁLISE DOS DADOS DA PESQUISA}

Os dados obtidos foram analisados a partir da leitura atenta das falas transcritas dos sujeitos entrevistados, através de categorias criadas, baseadas no referencial teórico apresentado no estudo e no conteúdo das entrevistas. As questôes que 
nortearam a pesquisa foram desenvolvidas a partir dos objetivos propostos, como

o significado do emprego e do desemprego.

Quadro 1 - Perfil dos participantes da pesquisa

\begin{tabular}{|c|c|c|c|c|c|c|c|}
\hline $\begin{array}{c}\text { Participantes } \\
\text { (nomes } \\
\text { fictícios) }\end{array}$ & Idade & $\begin{array}{l}\text { Estado } \\
\text { civil }\end{array}$ & Curso & Faculdade & Universidade & $\begin{array}{l}\text { Ano de } \\
\text { conclusão }\end{array}$ & Cidade \\
\hline Lucas & 29 & Solteiro & Filosofia & Letras & Agostinho Neto & 2011 & Luanda \\
\hline Augusto & 29 & Solteiro & Filosofia & $\begin{array}{l}\text { Ciências } \\
\text { Humanas }\end{array}$ & Agostinho Neto & 2011 & Luanda \\
\hline Pinto & 38 & Casado & $\begin{array}{l}\text { Contabilidade e } \\
\text { Auditoria }\end{array}$ & Economia & Agostinho Neto & 2010 & Luanda \\
\hline Kátia & 30 & Solteira & Pedagogia & Isced $^{1}$ & Agostinho Neto & 2011 & Luanda \\
\hline Carlos & 28 & Casado & Física & Ciências & Agostinho Neto & 2011 & Luanda \\
\hline Leão & 32 & Solteiro & $\begin{array}{l}\text { Contabilidade e } \\
\text { Auditoria }\end{array}$ & Economia & Agostinho Neto & 2011 & Luanda \\
\hline Sandra & 26 & Solteira & Direito & Direito & Agostinho Neto & 2010 & Luanda \\
\hline Paulo & 34 & Solteiro & Arquitetura & Engenharia & Agostinho Neto & 2011 & Luanda \\
\hline Adérita & 32 & Solteira & $\begin{array}{l}\text { Gestão e } \\
\text { Administração } \\
\text { Pública }\end{array}$ & $\begin{array}{l}\text { Ciências } \\
\text { Sociais }\end{array}$ & Agostinho Neto & 2011 & Luanda \\
\hline Álvaro Fonseca & 25 & Solteiro & Sociologia & $\begin{array}{l}\text { Ciências } \\
\text { Sociais }\end{array}$ & Agostinho Neto & 2012 & Luanda \\
\hline Mbaxi & 25 & Solteiro & Filosofia & Letras & Agostinho Neto & 2011 & Luanda \\
\hline Zé Manoel & 27 & Solteiro & Matemática & Ciências & Agostinho Neto & 2012 & Luanda \\
\hline Mbote & 27 & Solteiro & $\begin{array}{l}\text { Gestão e } \\
\text { Administração } \\
\text { Pública }\end{array}$ & $\begin{array}{l}\text { Ciências } \\
\text { Sociais }\end{array}$ & Agostinho Neto & 2012 & Luanda \\
\hline Masoxi & 26 & Solteiro & $\begin{array}{l}\text { Filosofia e } \\
\text { Economia }\end{array}$ & $\begin{array}{l}\text { Letras e } \\
\text { Economia }\end{array}$ & Agostinho Neto & 2011,2012 & Luanda \\
\hline Kakulo & 25 & Solteiro & $\begin{array}{l}\text { Línguas e } \\
\text { Literaturas }\end{array}$ & Letras & Agostinho Neto & 2012 & Luanda \\
\hline
\end{tabular}

Fonte: dados da pesquisa.

\subsection{CATEGORIAS}

\subsubsection{SENTIDO DO EMPREGO E DO DESEMPREGO}

A respeito desses conteúdos, os participantes relataram, a partir de suas experiências, tanto o sentido do emprego como do desemprego. Para alguns, o emprego representa, do ponto de vista social e psicológico, um elemento 
importante em suas vidas, porque constrói identidade e dá dignidade às pessoas. É visto como um fator essencial de socialização e de participação social, que proporciona ao sujeito o reconhecimento na sociedade. O emprego é também um caminho para a segurança social e para a satisfação das necessidades básicas, perfazendo, assim, o sentido de "estabilidade material e econômica" (Kátia).

Nessa perspectiva, Zanelli, Andrade e Bastos (2004) afirmam que o emprego transforma a realidade, viabiliza a sobrevivência e a realização do ser humano na sociedade. Em termos de conhecimentos práticos, para um participante da pesquisa desempregado, o emprego significa "Espaço para colocar em prática os conhecimentos adquiridos ao longo da formação" (Carlos).

Lhuilier (2011) afirma que ter emprego é ter a possibilidade de demonstrar, para si e para os outros, sua eficácia ocupacional, seu valor, além de poder colocarse à prova do real, em termos do que é possível, a partir das condiçóes históricas e sociais em que se formou.

Em relação ao desemprego, os participantes afirmaram que uma pessoa desempregada sofre rotulações, tanto na sociedade como na família. Ela é marginalizada e excluída. O termo marginal se refere, nesse caso específico, a alguém que é percebido pela sociedade como um ser fora do sistema produtivo, em virtude de uma inadaptação ao mercado de trabalho. Nesse sentido, a pessoa é marginalizada e estigmatizada socialmente, pelo fato de não ter um vínculo empregatício e não conseguir sustentar a si e à sua família. O desemprego priva a pessoa de seu sustento e da satisfação dos bens materiais.

Quanto ao significado psicológico, o desemprego foi descrito como uma situação desprazerosa, porque sugere a perda da capacidade de ação, por não satisfazer a alguns anseios, intensificando, desse modo, o sentimento de desgaste e de frustração. Santos (2008) afirma que uma grande frustração ocorre quando a pessoa não consegue ingressar no sistema produtivo, quando a sociedade exige que ela demonstre uma utilidade somente possível se ela tem trabalho remunerado, isto é, um emprego.

\subsubsection{IMPACTOS DO DESEMPREGO}

O desemprego tem consequências mais graves do que se pode imaginar, pois confina o sujeito, como já dissemos, numa situação de pobreza, marginalização, exclusão ou desfiliação social. Os desempregados são chamados de "inúteis para o mundo", pelo fato de não terem autonomia financeira e de serem incapazes de satisfazer a suas necessidades. Logo, são percebidos como fracassados. O indivíduo desempregado, sem trabalho, é definido por uma falta, e esta se torna 
o elemento principal de sua identidade social. O sujeito tem a sensação de que é sua própria existência que é recusada (Gaulejac, 2006).

A experiência de desemprego é vivenciada de maneiras distintas pelos egressos, levando mesmo a sentimentos de culpa e de arrependimento, o que constitui outra fonte de sofrimento. Para os participantes da pesquisa, essa situação é mais frustrante ainda quando o sujeito depende financeiramente de outras pessoas, ainda que de forma parcial. Isso é doloroso, e quando se trata, então, de dependência total, mais a situação se torna objeto de sofrimento. Essa dependência leva a uma frustração sem nome, provocando somatizaçôes como dores de cabeça ou perda de apetite. Outros sintomas também foram relatados, como a perda de vitalidade e das emoções. A falta do emprego pode ainda levar a pessoa a práticas como o alcoolismo ou a prostituição, no caso de mulheres (Kátia).

\subsubsection{INVISIBILIDADE E VERGONHA SOCIAL}

Segundo os entrevistados da pesquisa, o desemprego também leva a outras situações de sofrimento, como a invisibilidade e a vergonha social. O sujeito desempregado, ainda que tenha uma formação superior, não é percebido ou valorizado, tanto na sociedade como na família, pois aí ele não faz falta. $\mathrm{Na}$ sociedade angolana, de modo geral, e em Luanda, em particular, o que vale é a função ou o status social que a pessoa ocupa, não importa o nível acadêmico, se é ou não "doutor", o que interessa mesmo é ter um emprego, pouco importando se o salário é baixo. A invisibilidade social se relaciona à forma como são vistos os indivíduos sem emprego, ou seja, pessoas desprovidas de status social e de dinheiro. As pessoas "biscateiras" até parecem não ser percebidas como pessoas humanas, em sua dignidade. Um dos entrevistados disse: "No bairro onde moro, a maior parte das pessoas, ninguém dá por mim. Eu me considero mais um, porque não sou reconhecido nem respeitado [. . .] para mim, o emprego faz a pessoa aparecer" (Lucas).

Em relação à vergonha social, os participantes da pesquisa afirmam que, de fato, experimentam o sentimento de vergonha, ao falar de sua condição. Por exemplo, Mbaxi fala de sua experiência: "Eu tenho escondido a visão, o rosto, me distanciando de alguns amigos que têm bens materiais, para não me sentir triste e humilhado". Nessa situação, o desempregado apresenta uma postura de retraimento, por sentir-se assolado pela vergonha de não corresponder à expectativa social. Com efeito, quando o indivíduo não consegue um emprego, a vergonha surge como consequência do não reconhecimento social. Ela brota de uma inquietação, uma vez que o processo de identidade fica fragilizado, pois 
coloca o sujeito numa indefinição entre o olhar dos outros e o olhar de si para si mesmo.

Gaulejac (2006) afirma que a revalorização e o reconhecimento são necessidades primordiais para se ter lugar na sociedade, e que as pessoas, caso não tenham esse lugar, são malvistas e acabam se anulando. Quando se é socialmente definido por uma privação, por um déficit, ou considerado ainda "kunanga" (vagabundo), é difícil manter uma boa imagem de si. Gaulejac (2006) comenta ainda que a vergonha é um sentimento doloroso, sensível, que pode gerar o silêncio e aumentar a inibição do desempregado. Ela incomoda e cria desconforto. $\mathrm{O}$ indivíduo tomado pela vergonha sente-se inútil, desvalorizado e incompreendido. Isso leva a um sofrimento social e psíquico bastante doloroso. "A vergonha revela a totalidade da existência do indivíduo. A pessoa é envolvida na sua totalidade. Todos os registros da vida são afetados: sua subjetividade, sua intimidade, seus valores, suas crenças" (Gaulejac, 2006, p. 63).

\subsubsection{SALÁRIO}

Um ponto muito enfatizado pelos participantes é a questão salarial. Para alguns, o salário é "um elemento de planificação da vida e motivador para as pessoas se formarem. Ele cria estabilidade e assegura os valores no seio da família" (Álvaro Fonseca). Segundo Castel (2010), o salário assegura os direitos, dispõe os recursos para enfrentar não apenas situações como os casos de doença, mas também para o desfrute do lazer, permitindo uma participação ampliada na vida social, o que inclui o consumo, em geral, a habitação e a instrução. $\mathrm{Na}$ visão de Gaulejac (2006), a falta de dinheiro, na forma de salário, tem consequências subjetivas diversas. Aí se pode identificar a diferença entre a lógica das necessidades elementares, que exigem satisfação concreta, e o desejo que escapa à objetividade.

\subsubsection{FORMAÇÃO E EMPREGO}

$\mathrm{Na}$ realidade angolana, o desemprego em egressos da UAN se tornou um problema grave. Questóes entre o sistema educacional e o mercado de trabalho vêm ocupando um espaço crescente entre as preocupações dos estudiosos. No contexto de transformação socioeconômica em que o país vive, nem sempre a formação proporciona oportunidades de emprego, embora este não represente o único objetivo da formação. Os participantes afirmaram que muitos cursos da UAN foram abertos por vontade política e não técnica, ou por necessidade do mercado de trabalho. No entanto, como estamos constatando, ter uma 
formação superior, em Angola, não significa ter garantia de emprego, pois isso implica muito mais coisas como oportunidade, sorte, experiência de trabalho e apadrinhamento.

\subsubsection{ESTRATÉGIAS DE ENFRENTAMENTO}

Quanto a essa categoria, os sujeitos da pesquisa revelaram que vivem de biscates e outras atividades informais, porque o emprego está difícil. Por isso, veemse pessoas com nível acadêmico superior exercendo atividades que não exigem formação universitária. Como exemplo, a pesquisa encontrou um graduado em Contabilidade e Auditoria trabalhando como ajudante de mecânica, em uma empresa de prestação de serviços. Além disso, a pessoa que vive de biscates ainda se sente na mesma condição de desempregada. $\mathrm{O}$ acesso a rendimentos, à integração e a uma posição social, a satisfação de sentir-se útil e de ser reconhecido, dependem, em grande medida, do emprego. A possibilidade de exercer uma atividade de trabalho socialmente reconhecida é condição necessária para se atingir o status sonhado. Para os egressos que vêm biscatando a fim de satisfazer suas necessidades básicas, esse trabalho tem apenas um valor instrumental.

\subsubsection{HORIZONTE TEMPORAL}

A pesquisa evidenciou que o tempo de desemprego, na visão desses participantes, não se move. Os sujeitos sentem que o tempo está parado pelo fato de não fazerem nada. A experiência de um tempo que se dilata tem, na vida dos desempregados, um impacto negativo. Para eles, o tempo de desemprego é percebido como mais lento em relação ao tempo de emprego. Eles sentem que estão a perder, enquanto o tempo está a passar. Araújo (2011) escreve que o desemprego é uma circunstância psicossocial e econômica que leva a pessoa a outra forma de vivenciar o tempo, pois ela se vê impedida de levar à frente seus projetos pessoais, de exercer atividades que garantam sua inserção na vida cultural ou política. Trata-se, desse modo, de sujeitos impedidos de trabalhar, isto é, de exercer atividades que restabeleçam relações criadoras consigo mesmas, com o mundo e com o outro.

A sensação de tempo parado e de dias cada vez mais longos é o que é vivido pelos egressos desempregados, como se vê na fala de uma participante:

As coisas são muito difíceis mesmo para mim. O relógio parece parar, o tempo parece que não anda, o dia parece ser mais longo, cada dia que passa, parece que o dia vai se tornando mais longo, o hoje parece ser mais longo do que o ontem, já numa perspectiva daquilo que poderá ser o amanhã, tendo em conta que as atividades não 
se alteram. Quanto ao tempo, é uma das razões de maior frustração para mim, dessa maior sensação de sofrimento, acredito que o tempo torna as coisas mais difíceis ainda (Masoxi).

\section{CONSIDERAÇÕES FINAIS}

Esta pesquisa procurou estudar o significado da condição de desempregado, realçando os efeitos psicossociais do desemprego em egressos da Universidade Agostinho Neto (UAN), de Luanda, Angola. A partir da pesquisa realizada, conclui-se que a trajetória da escola para o mercado de trabalho abre mais portas para o desemprego do que para o emprego e é vivenciada como momento de desafios. Também demonstrou que nem sempre a formação superior é garantia de emprego, é apenas um indicador ou uma possibilidade. Nesse sentido, a universidade deveria promover uma formação que permitisse a seus estudantes serem capazes de enfrentar as dúvidas ou incertezas, no campo profissional, originadas pelo desemprego. Partindo das experiências narradas e vividas pelos egressos, pode-se afirmar que o desemprego revela a ideia e o sentimento de desestabilização dos modos de vida, com graves consequências individual, familiar e social. Muitas vezes, esses egressos da universidade são injustamente taxados e tratados como "kunanga", termo que, em Angola, como dissemos, designa a condição social de "vagabundo".

O desemprego, no caso angolano, é um problema social que não resulta da incapacidade individual, mas sobretudo das estruturas socioeconômicas e políticas, tal como geridas pelo governo. Isso tem a ver, em parte, com o problema endêmico da corrupção, que interfere, por exemplo, nos processos de seleção de vagas para o serviço público. As principais causas do desemprego de egressos encontradas na pesquisa estariam associadas, além de fatores estruturais (econômicos, políticos e sociais), já discutidos neste texto, à inadequação dos cursos ao mercado de trabalho, ao nepotismo, à corrupção e trocas de favores, bem como à consequente fragilidade pessoal dos egressos. De acordo com o relato dos participantes, há deficiência na formação escolar, no ensino geral e universitário. Essa é uma realidade inegável e insofismável. Com efeito, sabese que a qualidade da formação é um fator essencial para a geração direta de emprego, em todas as economias modernas. Essa formação é o melhor caminho a percorrer, para os jovens e adultos excluídos do sistema econômico, dadas as novas exigências e desafios do mercado profissional.

Observou-se que o atual sistema de educação forma grande quantidade de jovens, mas a oferta de emprego não está em áreas nas quais eles se habilitam. Também foi constatado que existe falta de critérios técnicos das instituiçôes 
públicas e privadas, no que tange ao processo de recrutamento de seus empregados. Acrescente-se ainda o fato de que muitas vagas aos cursos são compradas, e o valor varia entre 1500 a 4000 mil dólares americanos ou equivalentes, em Kwanza, a moeda angolana.

Pelos dados levantados, a pesquisa demonstrou que, de certa forma, as universidades teriam também uma parte de responsabilidade pelo desemprego de seus egressos. Hoje, o número de universidades triplicou no país, mas sua qualidade deixa a desejar. A causa desse aumento da oferta de cursos superiores é o lucro, o dinheiro, mas os cursos não têm qualidade, as pessoas querem apenas ter um título de licenciado, não importando sua competência, em muitos casos. Além disso, algumas empresas privadas não aceitam empregar pessoas sem experiência de trabalho, porque teriam de despender mais recursos financeiros na formação adicional desses novos empregados. Por isso, hoje, em Angola, há mais empregos especializados ocupados por profissionais estrangeiros, pois estes têm os requisitos exigidos pelas empresas.

A vida dos desempregados também é marcada, como já foi tratado acima, pela desestruturação da experiência temporal, uma vez que é o tempo produtivo que costuma ser valorizado, nas sociedades contemporâneas, como tempo de trabalho. Essa mesma desestruturação temporal vale para as referências espaciais, pois a falta de emprego pode privar o sujeito dos espaços de participação social. Em relação aos efeitos do desemprego, constatou-se também que eles afetam negativamente a subjetividade e a saúde do egresso da universidade de Luanda. Em suas falas, os participantes citaram sintomas como a falta de fome e dores de cabeça, acompanhados, como era de se esperar, de forte sentimento de desvalorização e, por conseguinte, de depressão.

No que diz respeito às táticas de sobrevivência, verificou-se que os egressos usam várias formas para "se virar" ou para lidar com essas situações, destacandose os biscates ou ocupações em outras atividades desvalorizadas, inadequadas à sua formação. Muitos desses egressos ainda recorrem às oraçôes para minimizar a frustração e o sofrimento causado pelo desemprego.

A pesquisa levantou pontos cruciais e apontou caminhos para as políticas públicas relativas aos problemas que envolvem o desemprego em Angola, tais como adequação dos cursos ao mercado de trabalho, implantação de estágios obrigatórios em todos os cursos da universidade, melhoria da qualidade do ensino público e privado nos níveis fundamental, médio e superior, criação de agências de emprego em nível nacional. A reflexão relativa a essas políticas levanos a reafirmar que qualquer sociedade se desenvolve por meio da educação, da transmissão e da produção de novos conhecimentos. 


\section{REFERÊNCIAS}

Angola. (2008). Secretaria de Estado do Ensino Superior. Grupo Técnico para a Implementação das Linhas Mestras para a Melhoria da Gestão do Subsistema do Ensino Superior do Governo de Angola. Luanda: Secretaria de Estado do Ensino Superior.

Angola. (2012). Instituto Nacional de Estatísticas. Anuário de estatísticas sociais: 2010. Luanda: INE.

Araújo, J. N. G. (2011). Trabalho e temporalidade. Cadernos de Psicanálise, 25(39), 35-59.

Banco Mundial. (2012). Juventude e emprego em África: a potencialidade, o problema, a promessa. Washington: Banco Mundial. Recuperado a partir de https://documents1.worldbank.org/curated/zh/556351468009643652/ pdf/538410WP0PORTU00Box385391B00PUBLIC0.pdf

Bardin, L. (2004). Análise de conteúdo. (3a ed.). Lisboa: Edições 70.

Beck, U. (2010). Sociedade de risco: rumo a uma outra modernidade. São Paulo: Ed. 34.

Bernal, A. O. (2010). Psicologia do trabalho em mundo globalizado: como enfrentar $o$ assédio psicológico e o estresse no trabalho. Porto Alegre: Artmed.

Castel, R. (2005). As metamorfoses da questão social: uma crónica do salário. (9a ed.). Petrópolis: Vozes.

Castel, R. (2010). As metamorfoses da questão salarial: uma crónica do salário. (9a ed.). Petrópolis: Vozes.

Constituição da República de Angola. (2010). Luanda: Assembleia Nacional.

Creswell, W. J. (2010). Projeto de pesquisa: métodos qualitativos, quantitativos e mistos. ( $3^{\mathrm{a}} \mathrm{ed}$.). Porto Alegre: Artmed.

Demazière, D. (2006). Introdução: uma abordagem sociológica do desemprego. In N. A. Guimarães, \& H. Hirata (Orgs.), Desemprego: trajetórias, identidades, mobilizações. (pp. 23-42). São Paulo: Editora Senac. (Série Trabalho e Sociedade). 
Diez, C. L. F., \& Horn, G. B. (2005). Orientações para elaboração de projetos e monografias. (2a ed.). Petrópolis: Vozes.

Gaulejac, V. (2006). As origens da vergonha social. São Paulo: Via Lettera.

Gourgel, A. (2012, 31 outubro). A economia de Angola. Jornal de Angola, 5.

Jahoda, M. (1987). Empleo y desempleo: un análisis socio-psicologico. Madrid: Morata.

Lei n. ${ }^{\circ}$ 1/06, de 18 de janeiro de 2008. (2008, 18 janeiro). Bases gerais da política que proporciona a inserção no mercado de emprego de jovens à procura do primeiro emprego, prioritariamente com idade entre os 16 e 30 anos. Angola. (2008a). Projecto Portal do Governo, Luanda. Recuperado a partir de http:// www.saflii.org/ao/legis/num_act/ldbdpe255.pdf

Lhuilier, D. (2011). Saúde e trabalho. Palestra. Belo Horizonte, UFMG.

Organização Internacional do Trabalho. (1997). Relatório da 5 a Reuniāo Bienal de Planificadores de Emprego em África. Abidjã: OIT.

Rocha, M. J. A. (2001). Os limites do crescimento econômico em Angola: as fronteiras entre o possivel e o desejável. Luanda: Executive Center, \& Luanda Antena Comercial.

Sanchis, E. (1997). Da escola ao desemprego. Rio de Janeiro: Agir.

Santos, M. (2008). Espaço dividido: os dois circuitos da economia urbana dos paises subdesenvolvidos. (2a ed.). São Paulo: Editora da Universidade de São Paulo.

Universidade Católica de Angola. (2010). Centro de Estudos e Investigação Científica. Relatório social de Angola. Luanda: Universidade Católica de Angola.

Universidade Católica de Angola. (2011). Centro de Estudos e Investigação Científica. Relatório econômico de Angola. Luanda: Universidade Católica de Angola.

Zanelli, J. C., Andrade, J. E. B., \& Bastos, A. V. B. (Orgs.). (2004). Psicologia, organizaçôes e trabalho no Brasil. Porto Alegre: Artmed.

(Footnotes)

1 Instituto Superior de Ciências de Educação, Luanda. 